University of Nebraska - Lincoln

DigitalCommons@University of Nebraska - Lincoln

Roman L. Hruska U.S. Meat Animal Research

U.S. Department of Agriculture: Agricultural Center

Research Service, Lincoln, Nebraska

$1-1-2021$

\title{
Evaluation of CD109, PCP4 and SEMA3D genes for their association with Ovine Johne's disease in Turkish sheep
}

\author{
Yalçın Yaman \\ Sheep Breeding and Research Institute, yalcinyaman@gmail.com \\ Ramazan Aymaz \\ Sheep Breeding and Research Institute \\ Murat Keleş \\ Sheep Breeding and Research Institute \\ Veysel Bay \\ Sheep Breeding and Research Institute \\ Ecem Hatipoğlu \\ Sheep Breeding and Research Institute
}

See next page for additional authors

Follow this and additional works at: https://digitalcommons.unl.edu/hruskareports

Part of the Beef Science Commons, and the Meat Science Commons

Yaman, Yalçın; Aymaz, Ramazan; Keleş, Murat; Bay, Veysel; Hatipoğlu, Ecem; Kaptan, Cüneyt; Başkurt, Atilla; Yilmaz, Onur; and Heaton, Michael P., "Evaluation of CD109, PCP4 and SEMA3D genes for their association with Ovine Johne's disease in Turkish sheep" (2021). Roman L. Hruska U.S. Meat Animal Research Center. 566.

https://digitalcommons.unl.edu/hruskareports/566

This Article is brought to you for free and open access by the U.S. Department of Agriculture: Agricultural Research Service, Lincoln, Nebraska at DigitalCommons@University of Nebraska - Lincoln. It has been accepted for inclusion in Roman L. Hruska U.S. Meat Animal Research Center by an authorized administrator of DigitalCommons@University of Nebraska - Lincoln. 


\section{Authors}

Yalçın Yaman, Ramazan Aymaz, Murat Keleş, Veysel Bay, Ecem Hatipoğlu, Cüneyt Kaptan, Atilla Başkurt, Onur Yilmaz, and Michael P. Heaton 


\title{
Evaluation of CD109, PCP4 and SEMA3D genes for their association with Ovine Johne's disease in Turkish sheep
}

\author{
Yalçın Yaman ${ }^{\mathrm{a}}$ (D), Ramazan Aymaz ${ }^{\mathrm{a}}$, Murat Keleşa ${ }^{\mathrm{a}}$, Veysel Bay ${ }^{\mathrm{a}}$, Ecem Hatipoğlu ${ }^{\mathrm{a}}$, Cüneyt Kaptan ${ }^{\mathrm{a}}$, \\ Atilla Başkurt ${ }^{\mathrm{a}}$, Onur Yilmaz ${ }^{\mathrm{b}}$, and Michael P. Heaton ${ }^{\mathrm{C}}$ \\ ${ }^{a}$ Department of Biometry and Genetics, Sheep Breeding and Research Institute, Bandirma, Balikesir, Turkey; ${ }^{\mathrm{b}}$ Department of Animal

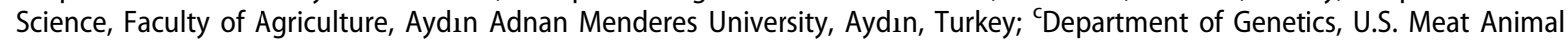 \\ Research Center, USDA, ARS, Clay Center, NE, USA
}

\begin{abstract}
Johne's disease is a chronic, contagious, zoonotic disease that affects numerous species including livestock and sometimes humans. The disease is globally distributed in sheep populations and caused by Mycobacterium avium Subsp. paratuberculosis (MAP). A previous genome-wide association study identified single nucleotide polymorphism (SNP) markers associated with OJD serostatus in CD109, PCP4, and SEMA3D genes. Our aim was to evaluate the same markers for association with OJD seroprevalence in Turkish sheep in a retrospective matched case-control study. The serological status for OJD in 1801 sheep was determined for four native and four composite breeds from three research flocks. One hundred eleven matched case-control pairs were constructed according to breed type and age from 1750 comingled ewes reared in the same environment. A Single Nucleotide Primer Extension (SNuPE) assay was designed to genotype PCP4-Intron 1, PCP4-3'UTR, SEMA3D, CD109-intron 2 and CD109-intron 8 markers and a McNemar's test was performed on the matched pairs. An association with these five markers was not detected with the OJD serostatus in Turkish sheep (power of detection, 0.95; odds ratio $>3$; McNemar's $p<.05$ ). Thus, a wider search may be needed to identify any major underlying genetic risk factors for OJD in Turkish sheep.
\end{abstract}

\section{KEYWORDS}

Paratuberculosis; Ovine

Johne's disease; genetic association; disease

susceptibility

\section{Introduction}

Paratuberculosis, also called as Johne's disease, is a chronic disease of the small intestine characterized with chronic granulomatous enteritis and progressive wasting. Paratuberculosis is contagious, zoonotic and affecting numerous species, including farm animals and humans. ${ }^{1,2}$ The causative agent of paratuberculosis is Mycobacterium avium Subsp. paratuberculosis (MAP). MAP is facultative, intracellular bacteria and obligated to host macrophages to reproduce itself. ${ }^{3-5}$ A wide range of host organisms has been reported for MAP infection, especially livestock, wildlife ruminants and birds. It is also reported that many insects and protozoa species can carry and transmit the MAP bacteria to susceptible hosts (reviewed by Ref. ${ }^{6}$ ) In addition to cross-species transmission from infected animals, MAP can survive in surface water, soil and manure for a long time owing to its spore-like state, thus, infection can be acquired from such environmental sources. ${ }^{7}$ Furthermore, MAP cannot be inactivated by pasteurization procedure, therefore, raw and/ or pasteurized milk and processed milk products (i.e., Baby formula, cheese, etc.) are potential risk factors, as well. ${ }^{8,9}$ Although its role is not well defined, MAP has been suggested as a potential causative agent of Crohn's disease, a chronic inflammatory bowel disease in humans. ${ }^{1}$ There are also concerns that MAP might be associated with other diseases such as sarcoidosis, Blau syndrome, Type 1 diabetes, Hashimoto's thyroiditis and multiple sclerosis. Additionally, MAP is thought to trigger autoimmune diabetes and autoimmune thyroiditis (reviewed by Ref. ${ }^{10}$ ) Regardless of controversy surrounding the evidence, the suggestion of MAP as an agent associated with human disease has significant implications for international marketing of affected livestock and increases its negative impact on livestock producers. 
Johne's disease is globally distributed in cattle and sheep. Two major strains been identified: are Type I (Type S), first cultured from sheep; and Type II (Type C), first cultured from cattle. Although the course of the infection is similar in cattle and sheep, chronic diarrhea is not a general feature in sheep in contrast to cattle. ${ }^{11}$ It is estimated that production loss due to Ovine Johne's Disease (OJD) in sheep is $4-5 \%$ in the UK, $1-4 \%$ in New Zealand and up to $7.8 \%$ in Australia. ${ }^{12}$ In sheep industry, classical control measures such as culling and restocking with uninfected sheep were found to be inadequate and/or not costeffective for the eradication of the OJD. ${ }^{13,14}$ Commercial vaccines against OJD are available in some countries. Vaccination with killed MAP $316 \mathrm{~F}$ strain reportedly reduced the mortality and achieved some success in reducing the prevalence of MAP shedding. However, it has been reported that multibacillary lesions found at necropsy of vaccinated sheep was shown to be shedding enormous numbers of MAP. ${ }^{15}$

Previous serological surveys and experimental infection studies indicated that there were breed-level differences in susceptibility to OJD. For example, finewool breeds (Merino and Corriedale) found to have a higher seroprevalence than others (Romney and composite breeds). ${ }^{2}$ In an experimental infection study, clinical disease was diagnosed at $42 \%$ in Merino and $36 \%$ in Merino $\times$ Suffolk crossbred, whereas 12 and $11 \%$ in Border Leicester and Poll Dorset, respectively. ${ }^{16}$ Despite the lack of information about economic loss, OJD is also prevalent in Turkish sheep breeds and there are some serosurvey studies reporting OJD seroprevalence from $8.3^{17}$ to $55.8 \% .^{18}$

Eradication of OJD from sheep with classical measures is time-consuming, expensive and not completely effective. Although some success has been achieved by vaccination for reducing the disease prevalence, shedding of MAP from vaccinated animals would probably continue. Consequently, vaccinated and unvaccinated sheep affected with OJD will remain as source of infection. If available, selective breeding for resistance to OJD could be an effective method when used as a complementary part of the classical eradication strategy. A number of candidate genes associated with individual resistance or susceptibility to OJD have been reported in sheep. NRAMP (SLC11A1) and MHC locus, ${ }^{19}$ TLR1, TLR2, and TLR $4^{20}$ genes were found to be associated with OJD prevalence. More recently, results of a Genome-Wide Association (GWA) study showed single nucleotide polymorphisms (SNPs) within SEMA3D, CD109, PCP4,
PRDM2, and ITFG2 genes were associated with OJD. ${ }^{21}$ Two missense variants in the coding region of the PCP4, and one in the CD109 genes were identified with the latter showing a strong linkage disequilibrium (LD) with an OJD-associated SNP on the Illumina OvineSNP50 BeadChip. ${ }^{22}$

In the present study, we used a retrospective cohort to determine OJD serostatus in four crossbreds and four native Turkish sheep breeds. Our aim was to use a matched case-control design to evaluate the potential association of previously reported SNP's ${ }^{21,22}$ within the CD109, PCP4 and SEMA3D genes with the serostatus of OJD in Turkish sheep.

\section{Materials and methods}

\section{Animals}

A total 1801 sheep from three different flocks from Sheep Research and Breeding Institute (SRI) (Bandirma/Balıkesir/Turkey) were included the study. Two tubes of whole blood samples with and without EDTA were collected for genetic and serological analysis from April to September in 2017. To allow sufficient time from seroconversion, only 2 -year-old and older sheep were included the study. Four native Turkish breeds; Karacabey Merino, Kivircik, Imroz (Gokceada), Chios (Sakiz) and four composite breeds; Ramlic (Rambouillet $\times$ Native Daglic), Hampshire crosses (Hampshire Down $\times$ Karacabey Merino), SBA (Black Head Merino $\times$ Karacabey Merino) and Bandirma (Black Head Merino $\times$ Kivircik) were sampled. The composite breeds except Ramlic have been developed in SRI to improve the meat yield. The native breeds; Kivircik, Imroz and Chios are conserved as genetic resources under the national 'Conservation and Sustainable Use of Animal Genetic Resources' project conducted by the Turkish government. These breeds are well adapted to their arid/ semi-arid extreme environments and are sustaining their productivity throughout hundreds of years at Aegean and Marmara regions of Turkey. Among them, the Imroz breed is native to Imroz island at the Marmara Sea and reared almost only on this island.

\section{Serological tests}

After centrifugation of fresh whole blood, serum samples were separated and kept at $-20^{\circ} \mathrm{C}$ until laboratory tests. All serum samples were subjected to indirect Enzyme-Linked Immunosorbent Assay (ELISA) using commercial test kits (Idexx Laboratories, Inc. Westbrook, USA). ELISA test was 
Table 1. Seropositive and seronegative matched pairs according to breed and age.

\begin{tabular}{|c|c|c|c|c|c|c|c|c|}
\hline Age (yr) & Karacabey Merino & Imroz & Kivircik & Bandirma & Ramlic & Hamph. Cross & SBA & Total \\
\hline 8 & - & - & - & 1 & - & - & - & 1 \\
\hline 7 & 6 & 1 & - & 3 & 1 & - & - & 11 \\
\hline 6 & 5 & - & 2 & 1 & 1 & - & - & 9 \\
\hline 5 & 18 & - & 5 & 2 & - & - & - & 25 \\
\hline 4 & 15 & - & 2 & 8 & - & 2 & - & 27 \\
\hline 3 & 18 & - & 1 & - & - & - & 2 & 21 \\
\hline 2 & 10 & 1 & 2 & 3 & - & 1 & - & 17 \\
\hline \multirow[t]{2}{*}{ Total } & 72 & 2 & 12 & 18 & 2 & 3 & 2 & 111 \\
\hline & $65 \%$ & $1.8 \%$ & $11 \%$ & $16 \%$ & $1.8 \%$ & $2.7 \%$ & $1.8 \%$ & $100 \%$ \\
\hline
\end{tabular}

performed following the manufacturer's instructions. ELISA plates were read at $450 \mathrm{~nm}$ wavelength using an ELISA plate reader (BioTek Instruments, Winooski, USA). Samples with ambiguous ELISA results were tested once again and the samples that still had ambiguous results were excluded from the study.

\section{Genetic analysis}

One-hundred eleven matched pairs (case-control) were identified among the retrospective cohorts and genetic analyses were performed on these sheep. Genomic DNA was extracted from whole blood with EDTA using commercial kits (General Biotechnology Co., Ltd., Seoul, Korea). DNA quality was confirmed via spectrophotometer (Optizen-NanoQ, Mecasys Co., Ltd, Daejeon, Korea). A multiplex Single Nucleotide Primer Extension (SNuPE) assay was designed for genotyping of the samples. Briefly, a multiplex Polymerase Chain Reaction (PCR) was used to amplify the targeted regions of DNA. The extension primers without fluorescent dye were designed in a specific length for each SNP and was expected to bind to preceding nucleotide of the targeted SNP. The ' $T$ ' tails were added to ensure that the extension primers were of different lengths for each SNP. Amplification and extension primers and rs numbers of the analyzed SNPs are provided in Supporting Information Table S1. The SNuPE reaction was performed using SNaPshot ${ }^{\mathrm{TM}}$ Multiplex Kit (Thermo Fisher Scientific Inc., USA) and capillary electrophoresis was used for fragment analysis protocol on Applied Biosystems 3500 genetic analyzer. To validate SNuPE genotyping assay, approximately $5-10 \%$ of the samples for each SNP were directly sequenced and the results were in $100 \%$ concordance.

\section{Statistical analysis}

Allele frequencies and Hardy-Weinberg equation was calculated using PLINK 1.07 software. ${ }^{23}$ Commingled ewe flocks in SRI have been reared under the same environmental and management conditions for more than 20 years, thus, exposure intensity and exposure durations to the MAP are assumed to be similar for all breeds. In an attempt to standardize the environment and exposure conditions, association analysis was performed only in flock 1 and flock 2 of SRI. The exception is Chios sheep (flock $3 ; n=51$ ) that are reared as a separate flock under different management conditions in SRI, therefore, this breed was not included in the association analysis.

Only ewes were included in the association study since exposure conditions of the rams can be different. Matched pairs of seropositive and seronegative ewes were constructed according to the age to minimize the differences between each animal's duration of exposure to MAP. Breed type was also added to pairing criteria to control the breed effect in the association study. As a result, a seropositive ewe was matched with a seronegative ewe with the same age, and breed type. In this way, 111 case-control matched pairs were constructed from a total of 1750 commingled SRI ewes. Age of sampled sheep was ranging from two to eight years (Table 1). A McNemar's test for correlated proportions was conducted ${ }^{24}$ on the matched pairs for both recessive and dominant models.

\section{Results}

\section{Distribution of OJD seroprevalence in breeds/flocks}

The overall seroprevalence of 1801 Turkish native and crossbred sheep tested was $7.2 \%$ (Table 2). All native and composite breeds tested were infected with OJD. Among the native and composite breeds with the highest seroprevalence was the SRI Chios flock ' 3 ' $(29.4 \%)$, which was reared in an isolated pen for 20 years and without direct contact with the other flocks, whereas the lowest prevalence detected in Imroz breed $(2.3 \%)$. Chios breed is considered to be high milk-yielding breeds. Taken together, the results suggest that OJD infection is widespread in Turkish 
sheep breeds, with the prevalence in some flocks exceeding $25 \%$ prevalence.

\section{Association of the CD109, PCP4 and SEMA3D variants with OJD serostatus in Turkish sheep}

Genetic analyses were performed with 111 matched case-control pairs ewes from SRI flocks which are K. Merino, Bandirma, Kivircik, Imroz, Hamph. Cross, Ramlic and SBA. Genotypes were obtained for all 222 samples (111 pairs) for CD109 and PCP4 SNP's, and all but 2 pairs for $S E M A 3 D$. The genotype frequencies revealed a number of SNPs are monomorphic in multiple breeds (Table 3). All but one SNP (CD109-intron 8) met Hardy-Weinberg expectations within breeds. The CD109-intron 8 SNP deviated in Karacabey Merino sheep from HW with a $p$ value of .003 . Informative matched case-controls pairs were assigned for each SNP where only one member of the pair had the genetic risk factor (i.e., the case had 2 copies of the risk allele but the control did not). Typically, a minimum of 25 informative pairs are needed for a statistically significant analysis. When the genetic risk factor was defined as exactly one copy of the assigned allele (i.e., dominant), there were more than 25 informative pairs for each candidate SNP except PCP4 3'UTR marker. When the genetic risk factor was

Table 2. OJD seroprevalence of sampled native and composite Turkish sheep.

\begin{tabular}{|c|c|c|c|c|c|c|}
\hline \multirow[b]{2}{*}{ Breeds } & \multirow{2}{*}{$\begin{array}{l}\text { Flock } \\
\text { ID }\end{array}$} & \multirow{2}{*}{ Locations } & \multirow[b]{2}{*}{$n$} & \multicolumn{2}{|c|}{ OJD serostatus } & \multirow{2}{*}{$\begin{array}{c}\text { Prevalance } \\
(\%)\end{array}$} \\
\hline & & & & Neg & Pos & \\
\hline K. Merino & 1 & Bandırma/ SRI ${ }^{\mathrm{a}}$ & 901 & 827 & 74 & 8.2 \\
\hline Kivircik & 2 & Bandırma/ SRI & 208 & 196 & 12 & 5.8 \\
\hline Imroz & 2 & Bandırma/ SRI & 86 & 84 & 2 & 2.3 \\
\hline Bandirma & 2 & Bandırma/ SRI & 366 & 348 & 18 & 4.9 \\
\hline Hampshire cross & 2 & Bandırma/ SRI & 102 & 98 & 4 & 3.9 \\
\hline Ramlic & 2 & Bandırma/ SRI & 51 & 49 & 2 & 3.9 \\
\hline SBA & 2 & Bandırma/ SRI & 36 & 34 & 2 & 5.6 \\
\hline \multirow[t]{2}{*}{ Chios } & 3 & Bandırma/ SRI & 51 & 36 & 15 & 29.4 \\
\hline & & Total & 1801 & 1672 & 129 & 7.2 \\
\hline
\end{tabular}

${ }^{\mathrm{a}}$ SRI: Sheep Research and Breeding Institute-Balikesir/Bandirma. defined as one or two copies (i.e., additive or dominant) of the assigned SNP allele, there were more than 25 informative pairs for each candidate SNP except PCP4-3'UTR. When the genetic risk factor was defined as having two copies (i.e., recessive) of the SNP allele, there were more than 25 informative pairs for all but PCP4-3'UTR and SEMA3D (Table 4).

Statistical power analysis was conducted by $\mathrm{G}^{*}$ Power $3.1^{26}$ using the real proportion of the discordant pairs with 0.95 of detection of power, OD $\geq 3$, and $p<.05$ criteria for each analyzed SNP. None of the candidate SNPs reached significance in McNemar's test $(p>.05)$ except CD109 Int. 8 in the 'one allele is protective' model ( $p$ value, .02) However, the OR did not meet our significance threshold of 3.0 for a risk factor, or 0.333 for a protective SNP (OR, 0.6). Consequently, these SNPs in the candidate genes (CD109, PCP4 and SEMA3D) were not detected to be associated with OJD serostatus in Turkish sheep.

\section{Discussion}

In this study, we performed a serological survey for OJD in four crossbred populations and four native sheep breeds from the SRI research flock in south Marmara region of Turkey. Due to chronic, subclinic nature of infection, most of seropositive sheep were asymptomatic. The native breeds; Kivircik, Imroz and Chios, have currently been conserved under a project of Republic of Turkey Ministry of Agriculture and Forestry entitled, 'Conservation and Sustainable Use of Animal Genetic Resources' and it is forbidden by regulation to cross them with other breeds. Unfortunately, OJD was prevalent among Turkish native, composite and dairy breeds ranging from 2 to $29 \%$.

Animal husbandry management types (extensive or intensive), stock density, pasture usage, climate, and so forth are important factors affecting exposure

Table 3. Minor allele frequencies (MAF) for candidate SNPs in Turkish sheep.

\begin{tabular}{|c|c|c|c|c|c|c|c|c|c|c|}
\hline \multicolumn{4}{|c|}{ Overal minor allele frequencies } & \multicolumn{7}{|c|}{ MAF according to breeds } \\
\hline SNP & ${\text { Allele }{ }^{a}}^{a}$ & Allele2 & MAF & K. Merino & Bandirma & Kivircik & Imroz & Hamph. Cross. & Ramlic & SBA \\
\hline PCP4-Int. $1^{\mathrm{b}}$ & $\mathrm{T}$ & $\mathrm{G}$ & 0.09 & 0.13 & 0.01 & $-^{\mathrm{c}}$ & 0.38 & - & - & - \\
\hline PCP4-3'UTR ${ }^{b}$ & $A$ & $\mathrm{G}$ & 0.04 & 0.05 & - & - & - & - & 0.13 & - \\
\hline SEMA3D & $A$ & $\mathrm{G}$ & 0.09 & 0.08 & 0.16 & - & - & 0.25 & - & - \\
\hline CD109-Int.2 & G & $A$ & 0.47 & 0.45 & 0.40 & 0.21 & 0.38 & 0.33 & 0.50 & 0.25 \\
\hline CD109-Int.8 & $A$ & $\mathrm{C}$ & 0.46 & 0.41 & 0.14 & 0.15 & 0.25 & 0.33 & 0.50 & 0.25 \\
\hline
\end{tabular}

a Minor allele.

${ }^{\mathrm{b}}$ Antisense strand.

'The minor allele was not detected. 
Table 4. McNemar's test for OJD association with SNP risk and/or protective alleles.

\begin{tabular}{|c|c|c|c|c|c|c|}
\hline \multirow[b]{2}{*}{$\begin{array}{l}\text { McNemars pair } \\
\text { status and test } \\
\text { statistics }^{\mathrm{a}}\end{array}$} & \multirow[b]{2}{*}{$\begin{array}{c}\text { McNemar's } \\
\text { quadrants } \\
\text { and equations } \\
\text { b }\end{array}$} & \multicolumn{5}{|c|}{ SNP ID (risk or protective allele) } \\
\hline & & PCP4 Int.1 (T) & PCP4 3UTR (A) & SEMA 3D (A) & CD109 Int.2 (G) & CD109 Int.8 (A) \\
\hline \multicolumn{7}{|l|}{$\begin{array}{l}\text { One copy of risk } \\
\text { and/or } \\
\text { protective allele }\end{array}$} \\
\hline 1,1 & ' $a$ ' & 5 & 0 & 3 & 32 & 11 \\
\hline 1,0 & ${ }^{\prime} b^{\prime}$ & 13 & 6 & 13 & 29 & 21 \\
\hline 0,1 & ${ }^{\prime} C^{\prime}$ & 13 & 8 & 15 & 27 & 37 \\
\hline 0,0 & 'd' & 80 & 97 & 77 & 23 & 42 \\
\hline Total pairs & $a+b+c+d$ & 111 & 111 & 108 & 111 & 111 \\
\hline Discrdant pairs & $b+c$ & 26 & 14 & 28 & 56 & 58 \\
\hline $\mathrm{OR}$ & $b / c$ & 1.0 & 0.8 & 0.9 & 1.1 & 0.6 \\
\hline Cl95 lower & - & 0.5 & 0.3 & 0.4 & 0.6 & 0.3 \\
\hline C195 upper & - & 2.2 & 2.2 & 1.8 & 1.8 & 1.0 \\
\hline McNemar's $\chi 2$ & $\begin{array}{l}(|b-c|- \\
1)^{2} /(b+c)\end{array}$ & 0.0 & 0.1 & 0.0 & 0.0 & 3.9 \\
\hline$p$ Value & - & .31 & .37 & .28 & .20 & .02 \\
\hline \multicolumn{7}{|l|}{$\begin{array}{l}\text { One or two copies } \\
\text { of risk and/or } \\
\text { protective allele }\end{array}$} \\
\hline 1,1 & $' a^{\prime}$ & 5 & 0 & 4 & 63 & 51 \\
\hline 1,0 & 'b' & 15 & 7 & 14 & 16 & 15 \\
\hline 0,1 & ${ }^{\prime} c$ ' & 14 & 8 & 15 & 23 & 24 \\
\hline 0,0 & $' d '$ & 77 & 96 & 76 & 9 & 21 \\
\hline Total pairs & $a+b+c+d$ & 111 & 111 & 109 & 111 & 111 \\
\hline Discordant pairs & $b+c$ & 29 & 15 & 29 & 39 & 39 \\
\hline OR & $b / c$ & 1.1 & 0.9 & 0.9 & 0.7 & 0.6 \\
\hline C195 lower & $-^{d}$ & 0.5 & 0.3 & 0.5 & 0.4 & 0.3 \\
\hline Cl95 upper & - & 2.2 & 2.4 & 1.9 & 1.3 & 1.2 \\
\hline McNemar's $\chi 2^{\mathrm{e}}$ & $\begin{array}{l}(|b-c|- \\
1)^{2} /(b+c)\end{array}$ & 0.0 & 0.0 & 0.0 & 0.9 & 1.6 \\
\hline$p$ Value & - & .29 & .39 & .29 & .14 & .09 \\
\hline \multicolumn{7}{|l|}{$\begin{array}{l}\text { Two copies of risk } \\
\text { and/or } \\
\text { protective allele }\end{array}$} \\
\hline 1,1 & ${ }^{\prime} a^{\prime}$ & 0 & 0 & 2 & 9 & 10 \\
\hline 1,0 & ${ }^{\prime} b^{\prime}$ & 2 & 1 & 9 & 23 & 24 \\
\hline 0,1 & ${ }^{\prime} c^{\prime}$ & 1 & 0 & 4 & 16 & 17 \\
\hline 0,0 & 'd' & 108 & 110 & 94 & 63 & 60 \\
\hline Total pairs & $a+b+c+d$ & 111 & 111 & 109 & 111 & 111 \\
\hline Discordant pairs & $b+c$ & 3 & 1 & 13 & 39 & 41 \\
\hline $\mathrm{OR}$ & $b / c$ & 2.0 & $n a^{f}$ & 2.3 & 1.4 & 1.4 \\
\hline Cl95 lower & - & 0.2 & na & 0.7 & 0.8 & 0.8 \\
\hline C195 upper & - & 22.1 & na & 7.3 & 2.7 & 2.6 \\
\hline McNemar's $\chi 2$ & $\begin{array}{l}(|b-c|- \\
1)^{2} /(b+c)\end{array}$ & 0.0 & 0.0 & 1.2 & 0.9 & 0.9 \\
\hline$p$ Value & - & .75 & 1.00 & .17 & .14 & .14 \\
\hline
\end{tabular}

a Each member of a case-control pair is assigned a value of ' 1 ' or ' 0 ' depending on whether the risk factor is present (1) or absent ( 0 ) and falls into one of four possible categories pair status categories: ' $1,1^{\prime} ;{ }^{\prime} 1,0^{\prime} ;{ }^{\prime} 0,1^{\prime}$; or ' 0,0 '. All subsequent test statistics are calculated from these values.

${ }^{\mathrm{b}}$ These are quadrants from the McNemar's contingency table for classifying pairs.

'The allele is defined as 'risk' if McNemar's ' $b$ ' quadrant value is greater than or equal to the ' $c$ ' quadrant value. The allele is defined as 'protective' if McNemar's ' $b$ ' quadrant value is less than the ' $c$ ' quadrant value.

${ }^{\mathrm{d}}$ These were calculated from more complex equations. The Cl95 intervals were calculated as $\mathrm{e}^{(\ln (\mathrm{OR})-1.96 \sqrt{(1 / b+b}+1 / c)}$ to $\mathrm{e}^{\left(\ln (\mathrm{OR})+1.966_{(1 / 1 / b}+1 / c\right)}$. The twosided exact $p$ value was calculated as twice the binomial probability distribution function with ' $b$ ' successes, ' $b+c$ ' trials and the probability of success set to .5 .

${ }^{\mathrm{e}}$ Continuity corrected. ${ }^{25}$

fNot applicable, too few discordant pairs.

intensity and consequently affecting OJD prevalence. The SRI ewes from flock 1 and 2 were best suited to the matched, case-control association analysis due to rearing at the same environmental and exposure conditions for years. ${ }^{22}$ have investigated the coding region variations of PCP4 and CD109 which might be in LD with associated anonymous markers. They found a missense mutation in exon 3 and four mutations in the $3^{\prime} \mathrm{UTR}$ of the PCP4, nevertheless, those mutations had low MAF and they were not in LD with the anonymous markers. On the other hand, a strong LD (0.79) between CD109 intron 2 marker and a missense mutation in the exonic region of CD109 was detected in Sarda and some other indigenous Italian sheep breeds. Allele distribution of the missense mutation in Sarda sheep was reported to be 0.25 for case and 0.54 
for control $(n=42)$. In the present study, one of the anonymous markers around the CD109 gene reached significant $p$ value with assumption that 'one allele is protective' ( $p, .02$; OR, 0.6). The OR detection limits of our study design with a $95 \%$ confidence interval were from 3 to 30 (Table 4), thus, OR value of such association was lower than our detection limits.

In conclusion, our serosurvey indicates that OJD is prevalent in Turkish sheep and breed-based seroprevalence has been detected up to $29.4 \%$. Within our detection limits, results of case/control association analysis did not reveal any association between OJD serostatus and PCP4-Intron 1, PCP4-3'UTR, SEMA3D, CD109-intron 2 and CD109-intron 8 anonymous SNP markers. Further research including more candidate genes and/or chip-based GWAS are needed to understand underlying host genetic factors regarding immune response to OJD in Turkish sheep.

\section{Ethical approval}

All animal procedures in the study were reviewed and approved by the local ethics committee of Sheep Breeding and Research Institute (Approval Number: 1282412).

\section{Disclosure statement}

No potential conflict of interest was reported by the author(s).

\section{Data availability}

Analyzed genotype data of the study are available from the corresponding author on reasonable request.

\section{Funding}

This research has been funded by the Republic of Turkey Ministry of Agriculture and Forestry, General Directorate of Agricultural Research and Policies (Project number: TAGEM/HAYSÜD/15/A01/P02/02-02).

\section{ORCID}

Yalçın Yaman (D) http://orcid.org/0000-0003-2705-2831

\section{References}

1. Feller M, Huwiler K, Stephan R, et al. Mycobacterium avium subspecies paratuberculosis and Crohn's disease: a systematic review and meta-analysis. Lancet Infect Dis. 2007;7(9):607-613.

2. Gautam M, Anderson P, Ridler A, Wilson P, Heuer C. Economic cost of Ovine Johne's disease in clinically affected New Zealand flocks and benefit-cost of vaccination. Vet Sci. 2018;5(1):16.
3. Bannantine JP, Stabel JR. Killing of Mycobacterium avium subspecies paratuberculosis within macrophages. BMC Microbiol. 2002;2:2-7.

4. Garvey M. Mycobacterium avium subspecies paratuberculosis: a possible causative agent in human morbidity and risk to public health safety. Open Vet J. 2018;8(2):172-181.

5. McNees AL, Markesich D, Zayyani NR, Graham DY. Mycobacterium paratuberculosis as a cause of Crohn's disease. Expert Rev Gastroenterol Hepatol. 2015;9(12): 1523-1534.

6. Biet F, Boschiroli ML, Thorel MF, Guilloteau LA. Zoonotic aspects of Mycobacterium bovis and Mycobacterium avium-intracellulare complex (MAC). Vet Res. 2005;36(3):411-436.

7. Lamont EA, Bannantine JP, Armién A, Ariyakumar DS, Sreevatsan S. Identification and characterization of a spore-like morphotype in chronically starved Mycobacterium avium Subsp paratuberculosis cultures. PLOS One. 2012;7(1):e30648.

8. Kirkwood CD, Wagner J, Boniface $\mathrm{K}$, et al. Mycobacterium avium subspecies paratuberculosis in children with early-onset Crohn's disease. Inflamm Bowel Dis. 2009;15:1643-1655.

9. Singh AV, Chauhan DS, Singh SV, et al. Current status of Mycobacterium avium subspecies paratuberculosis infection in animals \& humans in India: what needs to be done? Indian J Med Res. 2016;144(5): 661-671.

10. Sechi LA, Dow CT. Mycobacterium avium ss. paratuberculosis zoonosis - the hundred year war - beyond Crohn's disease. Front Immunol. 2015;6:96.

11. Gautam M, Ridler A, Wilson PR, Heuer C. Control of clinical paratuberculosis in New Zealand pastoral livestock. $N Z$ Vet J. 2018;66(1):1-8.

12. Bush RD, Windsor PA, Toribio JA. Losses of adult sheep due to Ovine Johne's disease in 12 infected flocks over a 3-year period. Aust Vet J. 2006;84(7): 246-253.

13. Fridriksdottir V, Gunnarsson E, Sigurdarson S, Gudmundsdottir KB. Paratuberculosis in Iceland: epidemiology and control measures, past and present. Vet Microbiol. 2000;77(3-4):263-267.

14. Taylor P, Webster S. 2005. Evaluation of eradication strategies for Ovine Johne's disease technical report https://seslibraryusydeduau/bitstream/handle/2123/ 933/OJD\%20001\%20Final\%20Reportpdf?sequence=1. Accessed September 05, 2019.

15. Reddacliff L, Eppleston J, Windsor P, Whittington R, Jones S. Efficacy of a killed vaccine for the control of paratuberculosis in Australian sheep flocks. Vet Microbiol. 2006;115(1-3):77-90.

16. Begg DJ, Purdie AC, Silva KDe, Dhand NK, Plain $\mathrm{KM}$, Whittington RJ. Variation in susceptibility of different breeds of sheep to Mycobacterium avium subspecies paratuberculosis following experimental inoculation. Vet Res. 2017;48(1):36.

17. Buyuk F, Celebi O, Akca D, et al. Estimated apparent and true prevalences of paratuberculosis in sheep herds of the Kars Region in Northeastern Turkey. Vet Med. 2014;59(No. 7):331-335. 
18. Çelik A, Turgutoglu H. Seroprevalence of paratuberculosis in cattle, sheep and goats in Burdur, Southwestern Turkey. Isr J Vet Med. 2017;72:30-36.

19. Reddacliff LA, Beh K, Mcgregor H, Whittington RJ. A preliminary study of possible genetic influences on the susceptibility of sheep to Johne's disease. Aust Vet J. 2005;83(7):435-441.

20. Bhide MR, Mucha R, Mikula I, et al. Novel mutations in TLR genes cause hyporesponsiveness to Mycobacterium avium Subsp. paratuberculosis infection. BMC Genet. 2009;10:21.

21. Moioli B, Andrea SD, Grossi LD, et al. Genomic scan for identifying candidate genes for paratuberculosis resistance in sheep. Anim Prod Sci. 2016;56(7): 1046-1055.

22. Moioli B, De Grossi L, Steri R, Pilla F. Identification of missense mutations in the PCP4 and CD109 genes to validate the effect of neutral genetic markers. Czech J Anim Sci. 2016;61(07):317-325.

23. Purcell S, Neale B, Todd-Brown K, et al. PLINK: a tool set for whole-genome association and population-based linkage analyses. Am J Hum Genet. 2007; 81(3):559-575.

24. McNemar Q. Note on the sampling error of the difference between correlated proportions or percentages. Psychometrika. 1947;12(2):153-157.

25. Edwards AL. Note on the correction for continuity in testing the significance of the difference between correlated proportions. Psychometrika. 1948;13(3): 185-187.

26. Faul F, Erdfelder E, Buchner A, Lang AG. Statistical power analyses using $G^{*}$ Power 31: tests for correlation and regression analyses. Behav Res Methods. 2009;41(4):1149-1160. 